\title{
Application of photovoltaic power generation in the construction of conservation oriented Campus
}

\author{
YANG Zhi-jun ${ }^{1, a}$, Han Ping-ping ${ }^{2, b}$ \\ ${ }^{1}$ Institute of Architectural design , Hefei University of Technology, Hefei 230009, China; \\ ${ }^{2}$ School of Electrical Engineering and Automation, Hefei University of Technology, Hefei 230009, \\ China ) \\ aemail:hfyzj1981@163.com, ${ }^{\mathrm{b}} \mathrm{Ih} 021211 @ 163 . c o m$
} Keywords: Distributed energy; PV power generation; conservation oriented campus; power quality;
stability

\begin{abstract}
Distributed energy is effective in the construction of conservation oriented campus, the campus power distribution system into the green renewable energy, can bring considerable economic benefits. Green renewable energy can reduce the environmental pollution and governance problems of the traditional production power, and solve the problem of non-renewable energy resources, bring good environmental benefits, economic benefits and social benefits. In this paper, the application model of distributed energy system in Colleges and universities is established by using Power Factory and the simulation data are obtain. According to the corresponding mathematical model, a curve for analysis is established. Finally, the voltage stability of the system is analyzed. In conclusions, The voltage stability of each node is improved, the node voltage level is improved, and the power quality is improved. The project is of great significance and this application can be extended to more places to save energy and make a greater contribution to protecting the environment for our social construction.
\end{abstract}

\section{Introduction}

In recent years, energy consumption in colleges and universities has become larger and larger. The use of renewable energy sources served as a method of energy saving has received more and more attention. Especially, the application of ground source heat pump and PV system have become more and more common. Reference [3] analyzes the comprehensive functions of solar power application in colleges and universities. Reference [4] discusses the comprehensive effects of PV power application in colleges and universities. Reference [5] study the application of BIPV technology in colleges and universities. Due to the limit of resource conditions, the application of wind energy is less, but it is also gradually in the pilot.

With the appearance of competitive retail power market and the breakthrough progress of new distributed power technology in recent ten years, the application range of PV power generation has become larger and larger. In the construction of conservation oriented campus ,ground source heat pump technology, PV system application technology, wind power technology and wind and solar complementary technology are taken into use continuously and receive great benefits. In foreign countries, PV power generation is used widely in construction of conservation oriented campus and green energy is specially favored. In large new-built public buildings, the application of new energy technology is usually required. In recent years,some provinces and cities in china have introduced some application requirements of new energy technology in large public buildings.

The application of distributed energy technology in colleges and universities will bring direct economic benefits and limitless social benefits: (1)Bring direct economic benefits and reduce electric bills. (2)Achieve resource conservation, energy conservation, reduce consumption of limited energy and emissions of harmful substances. (3)Achieve environmental friendly, promote environmentally-friendly mode of production in campus, form campus fashion and cultural 
atmosphere where everyone loves and protects environment and realize harmonious development of human and nature. (4)Achieve green campus and ecology target of building conservation oriented campus. (5) Educate undergraduates and cultivate their sense of 'conservation' through the idea of resource conservation and ecological protection.

In this paper, the application model of distributed energy in university system is established by using Power Factory. After running the simulation, corresponding simulation data are obtained. Then a curve for analysis is established according to the corresponding mathematical model. By comparing the system voltage stability before and after PV access, we can draw that, the voltage stability of each node is improved, the node voltage level is improved and the power quality is improved. The project is of great significance.

\section{Feasibility study}

\subsection{Light energy resources in Hefei}

Hefei area is rich in light energy resources. The total amount of solar radiation in Hefei is about $119 \mathrm{kcal} / \mathrm{square}$ centimeter. During the period of greater than or equal to $0{ }^{\circ} \mathrm{C}$, the total radiation is $113.0 \mathrm{kcal} /$ square centimeter while the total radiation is $87.8 \mathrm{kcal} /$ square centimeter during greater than or equal to $10^{\circ} \mathrm{C}$. The annual sunshine hours of Hefei are around 2000 hours which are more in north than south. The sunshine hours are also different in four seasons. Summer is the most, followed by spring and autumn, and winter the least.

\subsection{PV power generation output forecast}

(1) Pick one day as a sample in Hefei area for research, the change curve of temperature and light intensity are illustrated below:

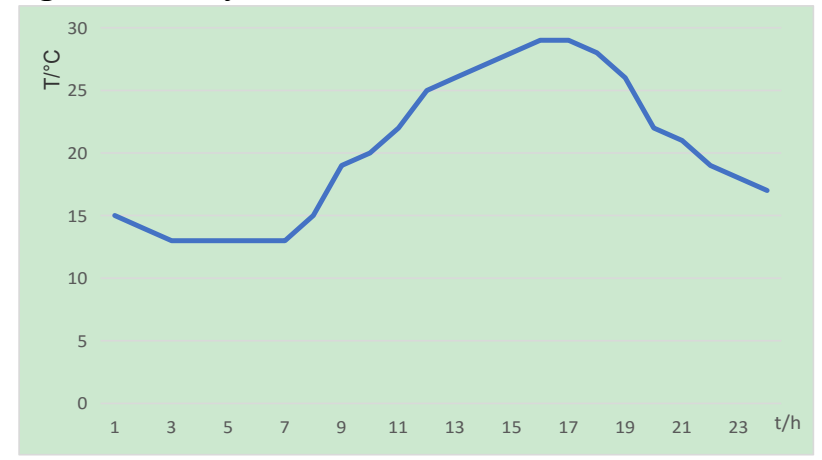

Fig. 1. The change curve of temperature

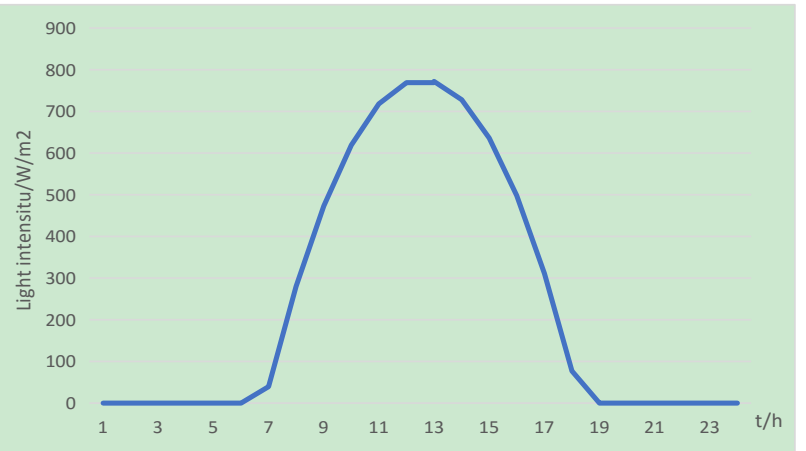

Fig.2. The change curve of light intensity

(2)By reference [8] the PV power output per unit area is

$$
P_{S}=\eta S I\left[1-\left(t_{0}+25\right)\right]
$$

Where $\eta$ is PV power conversion efficiency set as $20 \%$; $\mathrm{S}$ is PV power supply area, $\mathrm{m}^{2}$; I is the sun light intensity, $\mathrm{W} / \mathrm{m}^{2} ; \mathrm{t}_{0}$ is the real-time environment temperature, ${ }^{\circ} \mathrm{C}$.

According to that formula, the factors influencing the PV power generation output include photoelectric conversion efficiency of PV power, light intensity and environment temperature. The higher the conversion efficiency of the PV power, the greater the light intensity and the lower the environmental temperature is, the larger the PV output is.

According to the temperature and the light intensity data in Fig 1 2, the sample's real-time PV power data can be calculated by (1). Then the real-time curve of PV output per unit area is obtained: 


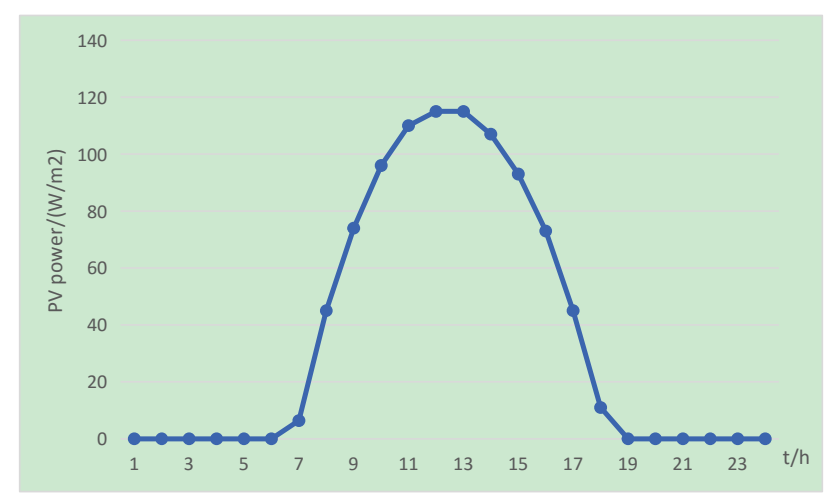

Fig.3 The real-time PV curve output per unit area

The maximum PV power value appears in 11 a.m when the light intensity is not maximum and the temperature is not lowest. This is the outcome of combined action of light intensity and environment temperature.

\subsection{Distribution system research in colleges and universities}

(1)In this paper, the distribution power system of the first switching station of Hefei university of technology is researched. Switching station gets the power from the different substation of $110 \mathrm{kv}$ by using $10 \mathrm{kv}$ line, i.e. there are two $10 \mathrm{kv}$ sources. Switching station has two buses independently. The important load is switched in the end of the points in substation.

Fig4 $\sim 5$ show the main electrical wiring diagram of switching station:

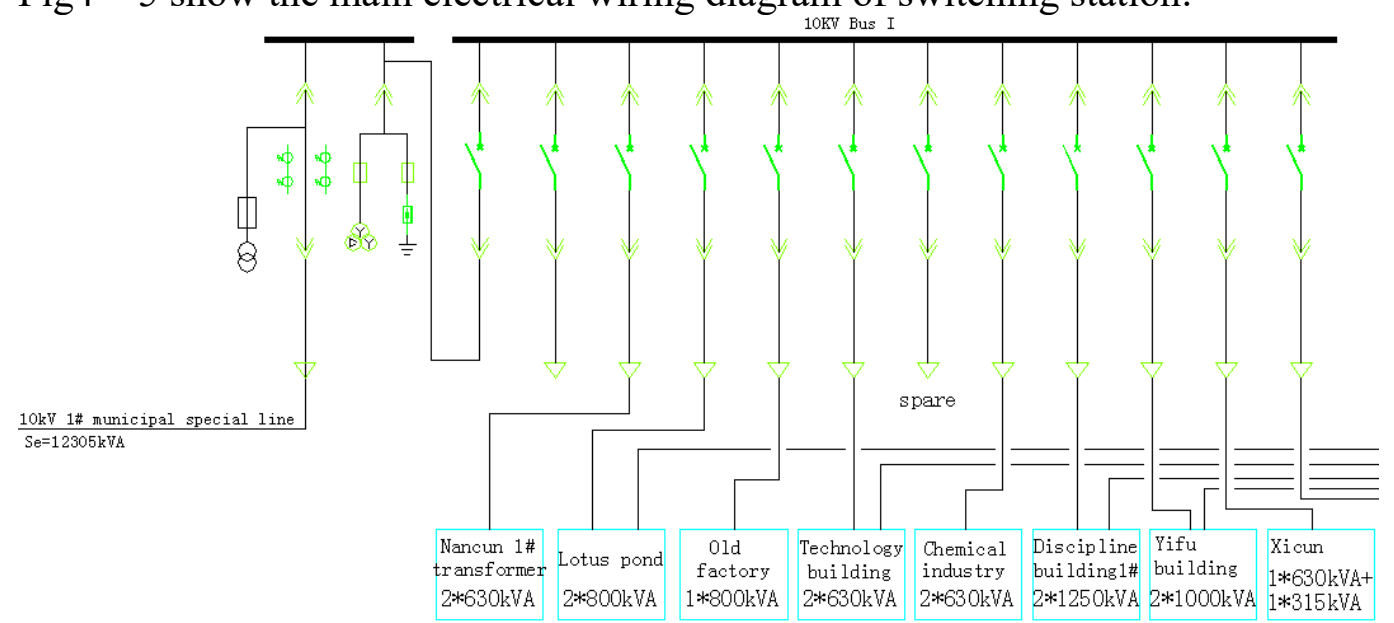

Fig.4. The main electrical wiring diagram of 1 \# source area

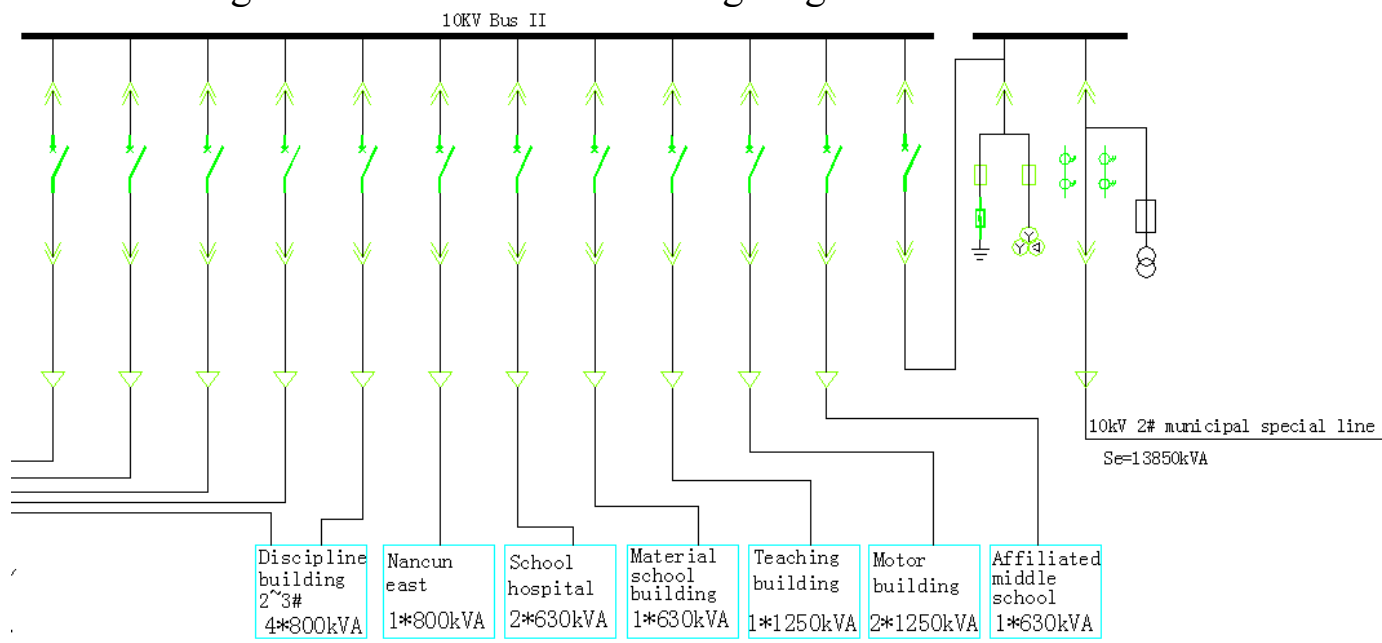

Fig.5. The main electrical wiring diagram of 2 \# source area

See from the main wiring diagram, the total installed capacity that two power supplies of the switching station is $26155 \mathrm{kva}$. The area that switching station covers has 15 substation, 27 transformers which using Dyn11 connection. switching station is linked with substation by 21 transmission lines which uses a method of laying cable. 
(2) the gross area of structure is approximately 500000 square meters in the old campus of hefei university of technology. In addition to the Family area of the zone, the roof is mainly flat roof. By the statistics, the roof which can be used in the area is about 50000 square meters. According to the switching station's loading area, the area that can be used as a power source is about 20000 square meters by using 10 buildings.

Based on this campus, we consider to design a total capacity of $\mathrm{Sn}=2000 \mathrm{kw} \mathrm{PV}$, according to the real-time PV array output per unit area table on step 2, there is maximum photovoltaic power at 11 o 'clock, Psmax $=115.37 \mathrm{~W} / \mathrm{m}$ squared, using the formula:

$$
S=S_{n} / P_{s \max }
$$

By equation (2), the area of the PV power generation system is $\mathrm{S}=17335.53 \mathrm{~m} 2$, the scheme is feasible in the available area.

\subsection{Research significance}

(1) Economic benefits

We developed calculation based on result of design of PV capacity in section 1.3.And by calculating the integral real-time curve of PV array output per unit area, it is concluded that per unit area electrical unit output on total sample day is about

$\mathrm{Ws}=\mathrm{W} 1 * \mathrm{~s}=15471.96 \mathrm{kWh}$

Campus electricity price is 0.55 yuan $/ \mathrm{kWh}$, so we can get that we can save energy expenditure for the school by inserting $2000 \mathrm{kw}$ PV on sample day:

$\mathrm{Mm}=0.55$ yuan $* \mathrm{Ws}=8509$ yuan

Calculated at 200 days a year, we can save energy expenditure for the school in a year:

$\mathrm{M}=200$ day $* \mathrm{Mm}=170$ ( ten thousand yuan)

(2) Environmental benefits

According to the designed system, on sample day, saving coal raw materials [9] :

$\mathrm{T}=0.321 \mathrm{~kg} / \mathrm{kWh} * \mathrm{Ws}=4.9665 \mathrm{t}$

By using PV to product power relative to the use of coal, we can reduce the quality of the discharge of pollutants for:

$\mathrm{M}\left(\mathrm{CO}_{2}\right)=\mathrm{T} * 2.6=12.9129 \mathrm{t}$;

$\mathrm{M}\left(\mathrm{SO}_{2}\right)=\mathrm{T} * 0.0085=0.0422 \mathrm{t}$;

$\mathrm{M}(\mathrm{NOx})=\mathrm{T} * 0.0074=0.0368 \mathrm{t}$;

$\mathrm{M}$ (dust emission) $=\mathrm{T}^{*} 0.2=0.9933 \mathrm{t}$;

As a result, it can be seen that PV grid application in the construction of a conservation-minded campus brought huge environmental benefits and social benefits.

\section{Power load characteristics and forecast}

\subsection{Power load characteristics}

Loads in university are divided into teaching load、research load、office load、 life load and so on. In college of science and engineering, the loads of teaching, science research and office electricity are similar so they are classified as scientific research electricity, among which the research load is the biggest consumer of electricity. Loads of scientific research increase at 7:00 in the morning, and go up to the top at 11:00. After the top, loads go down slightly but still keep a high consumption. The loads which shown in Fig.6 go down after 17:00 in the evening. Student dormitory and relational area belong to live loads, and such loads increase at 8:00 in the morning including class time and rest time at noon. Loads change a little during class time in the afternoon, but increase from 17:00 to 20:00 to the top and then gradually decline. As shown in Fig.7. 


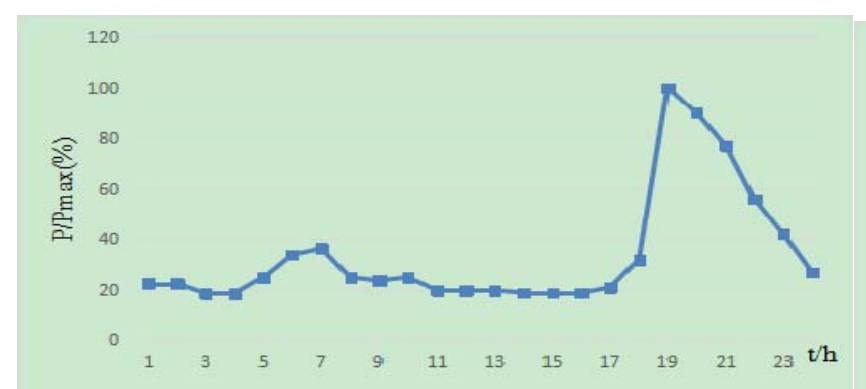

Fig.6 characteristics of Scientific research unit

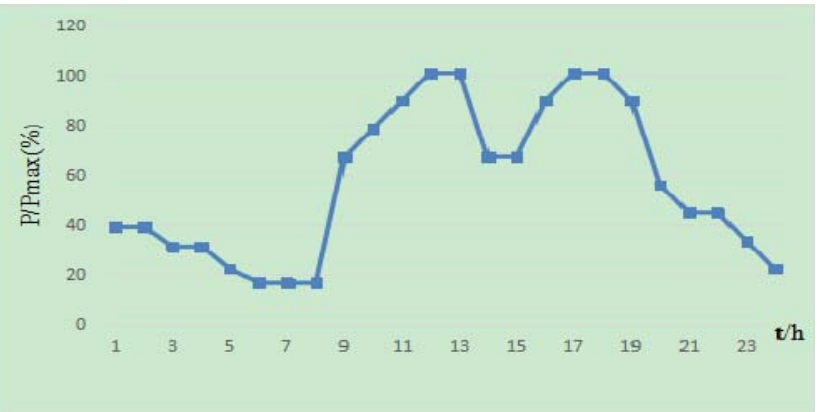

Fig.7 characteristics of living area

\subsection{Load forecast}

According to the actual circumstance of our campus, loads of the Nancun 1\# transformer、 the lotus pond transformer、 the Xicun transformer and the Nancun east transformer are part of life electricity load. The old factory transformer、 the technology building transformer v the east chemical industry building transformer、 the teaching building1\# transformer、Yifu building transformer、school hospital transformer、 the material building transformer v the teaching building transformer、 the motor building transformer and the transformer of the affiliated middle school of HFUT are part of science research load. Through calculation, active power and reactive power of each load bus could be known and the load curve as shown in Fig 8 to 12.

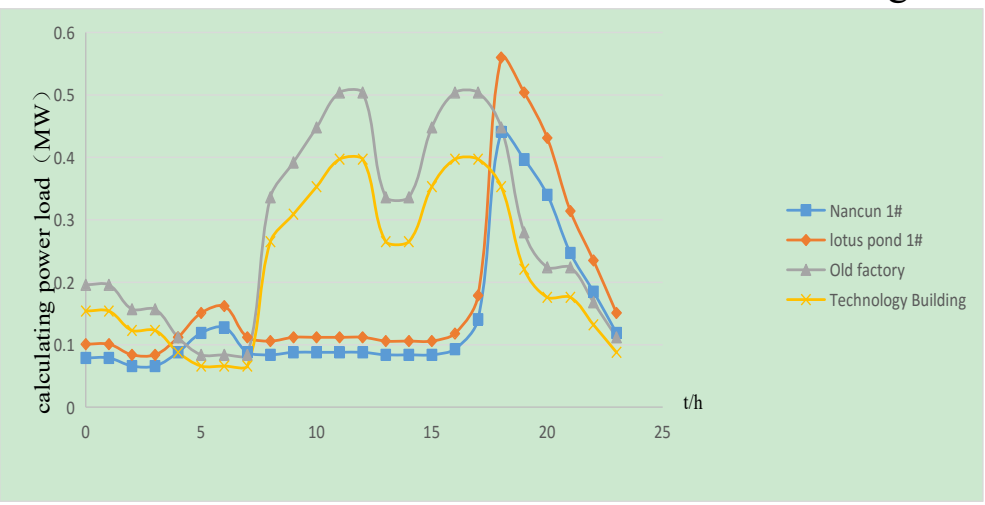

Fig. 8 The No.1 change curve of calculating power load

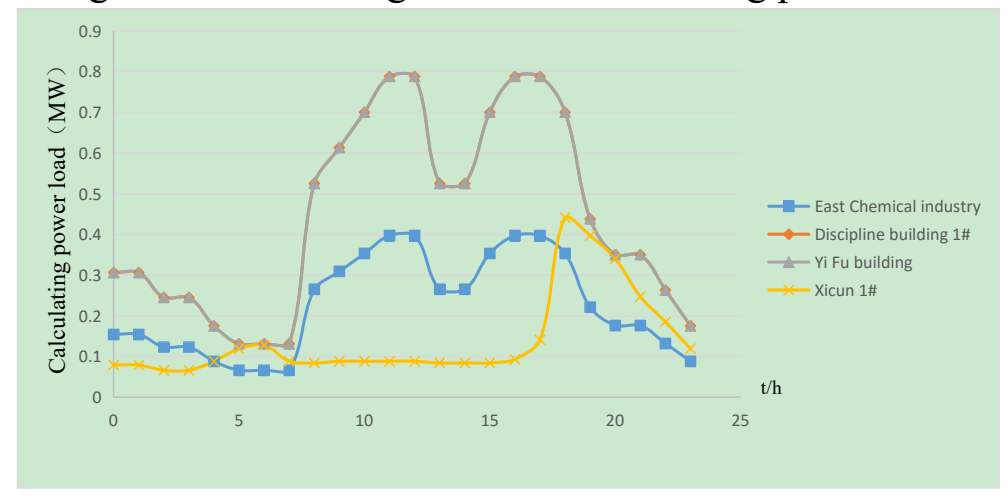

Fig.9 The No.2 change curve of calculating power load 


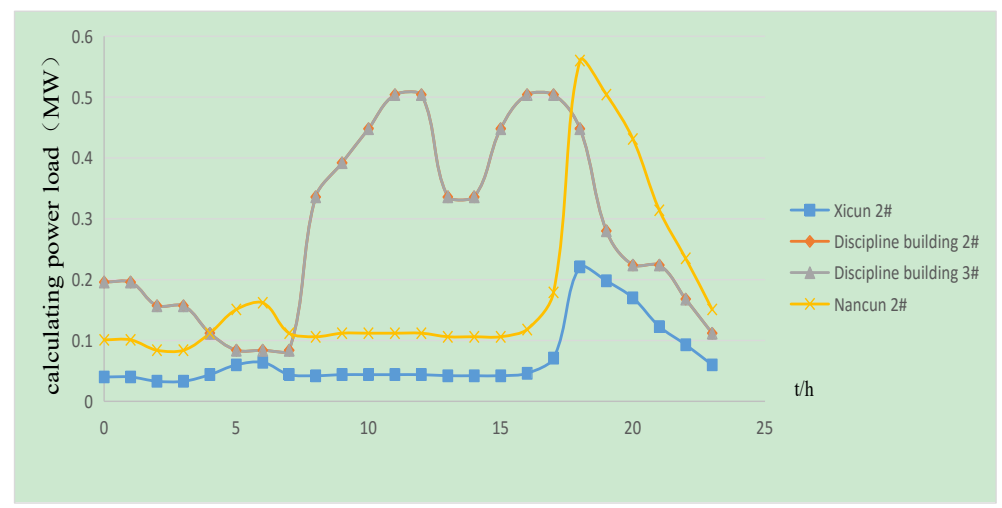

Fig.10 The No.3 change curve of calculating power load

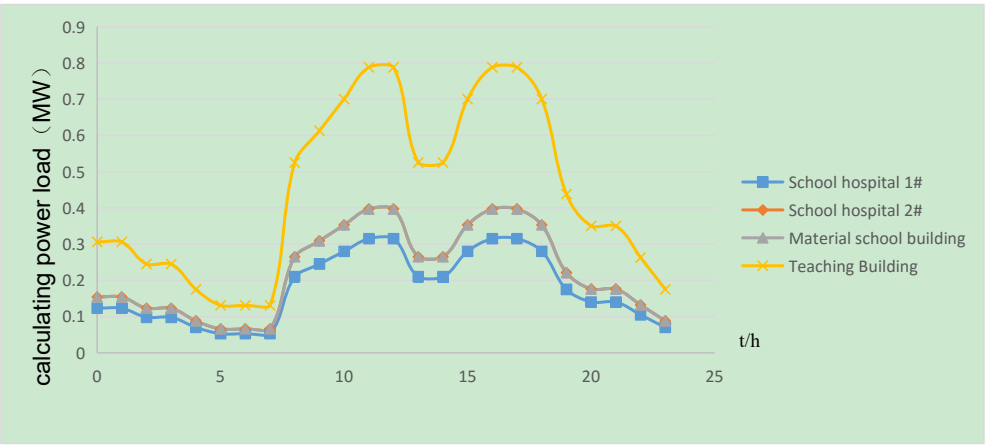

Fig. 11 The No.4 change curve of calculating power load

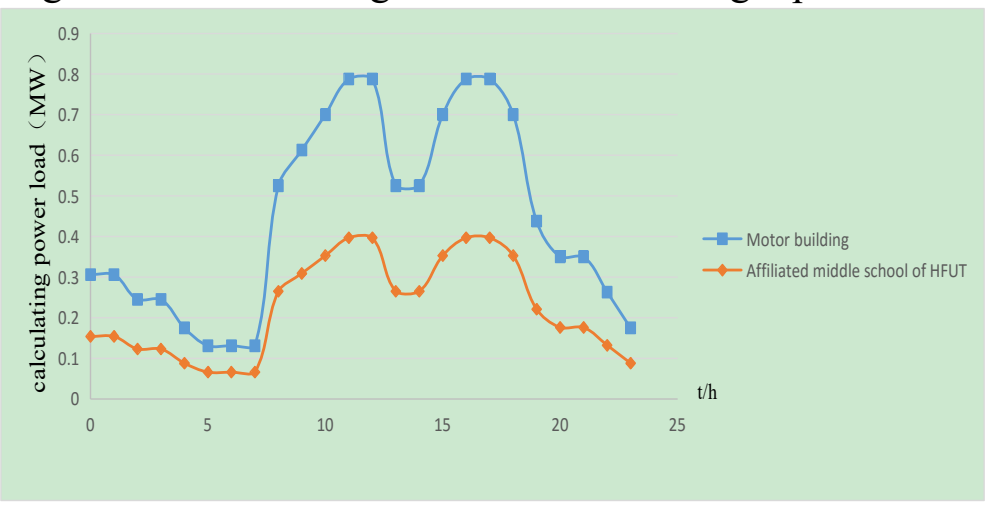

Fig.12 The No.5 change curve of calculating power load

\section{Design of scheme and simulation model}

\subsection{Design scheme of access system}

According to the main electrical wiring diagram of Hefei University of Technology and load forecast, PV access system model is established in Power Factory as follow:

Plan A: The total capacity of PV power generation device will be distributed equally into ten parts and then the ten parts will be connected to selected 10 typical load side. The reason of not connecting capacity to all of the load nodes is to save cost, materials and space, while the disadvantages of this approach is that the results are roughly and the adjustment effect is not obvious for grid.

Plan B: The total capacity of PV power generation device will be distributed proportionally according to the 10 typical load size and then the ten parts will be connected to the grid.

Comparing the plan A and plan B, plan B is more reasonable. It is not only saving the cost, but taking more effective use of PV power generation and making its voltage regulation effect to all grid nodes obvious. So the plan B is chosen.

According to the actual circumstance of campus building roof, the study chooses old factory substation 、 technology building substation、Yifu building substation、 discipline 1\#, 2\# and 3\# building substation, teaching building substation and motor building substation as PV system 
access points.

\subsection{Simulation model}

According to the plan B, an application model was built in PowerFactory about distributed energy resource of power distribution system of Hefei University of Technology, as shown in Fig13.

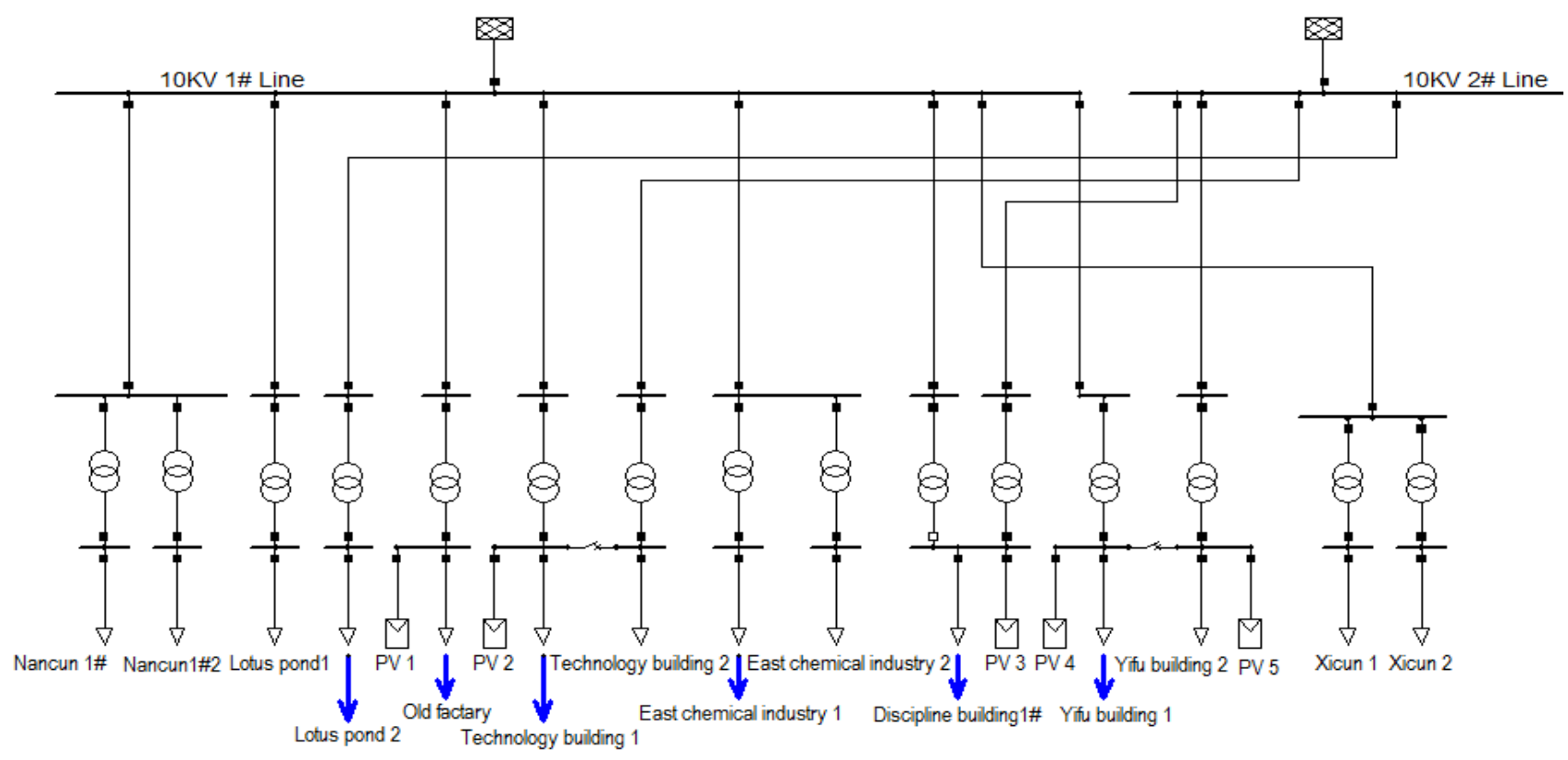

Fig.13 PV access system topology

In the power system simulation model of Hefei University of Technology, thinking about Actual use area of roof PV power generation device capacity allocation in access points are as follows:

Table 1 Statistics of capacity distribution of PV access point unit: MW

\begin{tabular}{|c|c|c|c|}
\hline Num & access point & calculated load & PV access capacity \\
\hline 1 & Old factory substation & 0.56 & 0.15 \\
\hline 2 & Technology building substation 1* & 0.441 & 0.11 \\
\hline 3 & Discipline building 1\# substation 1* & 0.875 & 0.24 \\
\hline 4 & Yifu building substation 1* & 0.7 & 0.19 \\
\hline 5 & Yifu building substation 2* & 0.7 & 0.19 \\
\hline 6 & Discipline building 2\# substation 1* & 0.56 & 0.15 \\
\hline 7 & Discipline building 2\# substation 2* & 0.56 & 0.15 \\
\hline 8 & Teaching building substation & 0.875 & 0.24 \\
\hline 9 & Motor building substation 1* & 0.875 & 0.24 \\
\hline 10 & Motor building substation 2* & 0.875 & 0.24 \\
\hline
\end{tabular}

\subsection{Analysis of simulation result}

According to the simulation results the node voltage change rate was calculated and then making each load node voltage change rate curve. Then analyse voltage stability of power system. Voltage change rate formula:

$$
\varepsilon=\frac{U^{\prime}-U}{U} \times 100 \%
$$

Where U' is nodes voltage after connecting PV,U is nodes voltage before connecting PV.

After the system is merged with PV power supply, Load node voltage change rate as shown in Fig 14.In the figure abscissa is the time of illumination in a day, in this paper, we choose 6:00 a.m to 5:00 p.m, ordinate is the percentage of load node voltage change rate. 

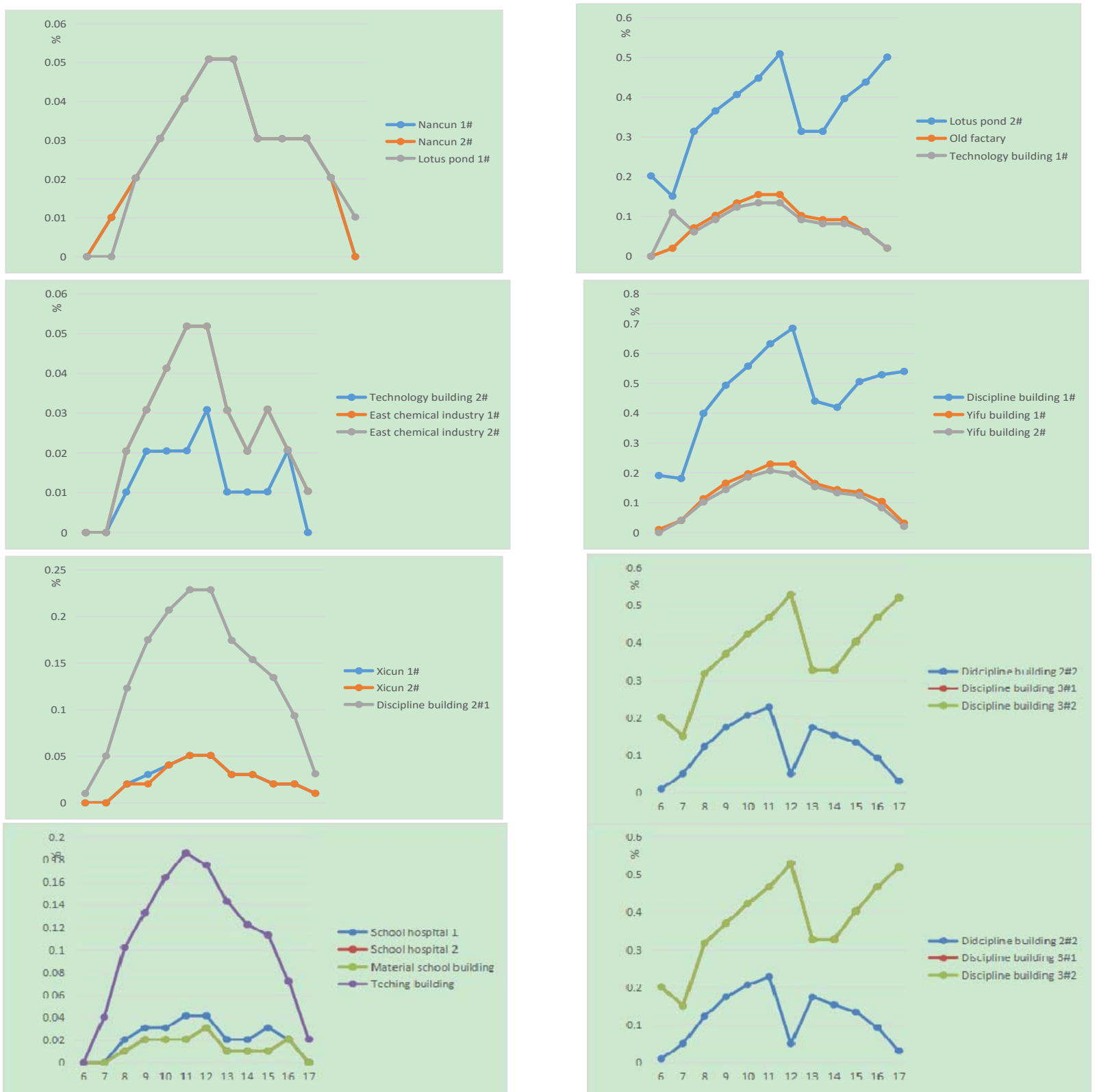

Fig 14. The voltage change rate curve of Load node

We can know from Fig 14 that ten load nodes connected with PV power have rising voltages after the distributed PV power supply are merged into power system. The Discipline building 1\# voltage rise up to $0.7 \%$. The voltage of other load nodes without the PV power supply also increase slightly. The lotus pond voltage rise up to $0.5 \%$.

\section{Conclusions and prospect}

Based on the distribution system of Hefei university of technology, the influences on distribution network after distributed PV power generation access are studied. The application model of distributed energy system in colleges and universities is established in PowerFactory. After simulation and experimental data analysis, the conclusions are as follows:

(1) The effective application of Distributed energy in the construction of a conservation oriented campus immits green renewable energy to the campus distribution system.

(2) The cost of energy expenditure in the campus achieve considerable economic benefits.

(3) PV power generation can save fossil energy and reduce the use of coal and carbon dioxide emissions to bring huge social benefits.

(4) The capacity of PV access is determined according to the proportion of load size. That not only reduces the cost of input, but also makes voltage regulation effect on the grid node obvious. 
(5) After merged with PV in distribution network system, load voltage, power quality and system stability are improved.

Subsequent possible research content:

(1) Expand the scope of the PV trial point by trying to put into use in the resident area, and analyze the impact of the system capacity and increasing PV panels on the entire operating system.

(2) Improve the efficiency of the PV power device problem.

\section{References}

[1].Sun Deqiang, Zheng Junwei, Zhang Tao, et al.The Utilization and Development Strategies of Smart Grid and New Energy[C].2010 Asia-Pacific Power and Energy Engineering Conference.March 2010.

[2].Elmer Collins, Michael Dvorack, Jeff Mahn, Michael Mundt, and Michael Quintana. Reliability and availability analysis of a fielded photovoltaic system[C].Photovoltaic Specialists Conference (PVSC), 2009 34th IEEE.June 2009:2316-2321.

[3].Li Xiaoxiong. Photovoltaic power generation system and its analysis of integrated effect in colleges and universities[J].Technology Innovation and Application.2013 33th:4-5.

[4].Yan Shisheng, Zhong Chengyao. The feasibility analysis of 3MW concentrating BIPV efficient power generation project in HaiNan Nomal Uiversity[J].Clean energy and New energy. 2009,12:350-352.

[5].Cai Bing, Xu Yanyan. Comprehensive benefit research on roof photovoltaic power station construction in colleges and universities[J]. South Agricultural Machinery.2014,10:32-33.

[6].Yang Zhijun, Wu Hongbing, Ding Ming. Control strategy research on doubly-fed wind power generation system when failure occurred[J].Power system protection and control. 2010,01:14-18.

[7].Zhao Jie. Related technology research on Grid-connected Photovoltaic power generation system[D].Tianjin:Tianjin University. 2012.

[8].Wang Min, Ding Ming. Distributed generation and its benefits[J]. Journal of hefei university of technology(Natural science). 2014,4:354-358.

[9].Zhu Baotian. The environmental costs evaluation of thermal power emission[J]. Thermal Power Research Institute. 710032.

[10].Yang Zhijun, Cao Chengfu. University students' apartment electricity load characteristics and the distribution of economic operation[J]. Engineering and Construction. 2008,22(4):512-514. 